Resenha:

\title{
Vigilar la sociedad. Estudios discursivos sobre inteligencia poli- cial bonaerense, organizado por María Alejandra Vitale
}

\author{
Israel de Sá ${ }^{1}$
}

O trabalho com e sobre a memória se efetua em diferentes campos das ciências humanas: da psicanálise aos estudos da linguagem, passando pela história e a filosofia. A articulação entre língua, história, sujeito e memória ganha particular interesse nos estudos discursivos que, constituídos na interdisciplinaridade e debruçados sobre arquivo e corpora de textos históricos e políticos (oficiais ou não), buscam apreender efeitos de sentido e compreender, muito mais que o passado, o próprio presente. A memória é, então, nessa perspectiva, também efeito, uma vez que se produz em condições históricas de emergência e não estabiliza sentidos únicos na medida em que a própria verdade é igualmente processo.

É justamente na problemática que envolve memória, história, arquivo, discursos e (efeitos de) sentidos que se inscreve a obra Vigilar la sociedad. Estudios discursivos sobre inteligencia policial bonaerense, organizada por María Alejandra Vitale, importante pesquisadora dos estudos retóricos e discursivos, e publicada pela editora argentina Biblos em 2016. Produto de uma ampla investigação, subsidiada pela Universidad de Buenos Aires (UBA), o livro propõe-se a uma volta aos arquivos da repressão argentina, instituídos no final da década de 1950, ao investigar o Arquivo da Dirección de Inteligencia de la Policía de la Provincia de Buenos Aires (DIPBA). Os arquivos da repressão, objeto central do livro, constituem-se de fundos documentais produzidos por instâncias repressivas legais ou ilegais das forças de segurança.

O período abordado no estudo engloba o momento imediatamente posterior ao golpe e à queda de Juán Domingo Perón, quando se institui uma política repressiva de segurança nacional, passa pela violenta ditadura militar do final da década de 1970 e início dos anos 1980, pela transição, e chega ao período democrático dos anos 1980 e 1990. A DIPBA é um órgão significativo desse amplo período por ter sido criada em 1956 - um ano após o golpe de Estado que derrubou Perón, em meio ao contexto da Guerra Fria e, especialmente, à virada socialista que promoveu a Revolução Cubana -, quando estabeleceu uma verdadeira atividade de inteligência, e persistido até o ano de 1998, contemplando 15 anos de democracia - no início dos anos 2000 seus arquivos tornaram-se públicos como consequência das políticas de memória daquele país.

Nesse sentido, a abordagem teórica em torno de dado aspecto histórico (repressão e ditaduras), por si, e antes mesmo de nos atentarmos para as análises aí desenvolvidas, já representa grande relevo para discussão no Brasil. Aqui ainda são poucos os trabalhos que tratam do período repressivo e ditatorial brasileiro e ainda em menor número aqueles que se debruçam sobre nossos "arquivos da repressão". Isto se deve, ao menos, por dois motivos: i) os processos de transição e redemocratização brasileiros aliados a uma democracia enfraquecida dos anos 1990 e 2000 impossibilitaram a consolidação de um "dizer a ditadura" e da emergência de memórias da resistência; ii) em detrimento dos trabalhos da Comissão Nacional da Verdade, desenvolvidos tardiamente entre 2012 e 2014, e da

1 Professor adjunto do Instituto de Letras e Linguística da Universidade Federal de Uberlândia (ILEEL/UFU). 
Lei de Acesso à Informação, de 2010, ainda muitos documentos produzidos pelos órgãos de inteligência do Regime Militar não estão acessíveis nem mesmo a pesquisadores, o que limita o trabalho de arquivo. Nesse sentido, a obra aqui analisada constitui, já por sua abordagem teórica e temática, paradigma para os estudos aqui até então incipientes e nos incita ainda mais à reivindicação de acesso aos arquivos da repressão brasileira.

No que diz respeito, então, aos aspectos metodológicos do trabalho, vale ressaltar, inicialmente, e como aponta Vitale na sua apresentação, que o trabalho com o Arquivo nem sempre foi prioridade nos estudos retóricos e discursivos e, especificamente nesses campos, quase nunca se tornou objeto de interesse na Argentina. No que se refere, contudo, aos chamados "arquivos da repressão", que ganharam visibilidade nas últimas décadas naquele país, as pesquisas em análise do discurso demonstraram particular interesse, tomando-o como um desafio ao incorporá-lo como objeto de suas investigações. É, portanto, a partir da perspectiva francesa da Análise do Discurso, dialogando, ainda, com estudos em retórica e da nova história, que esse trabalho de pesquisa e análise de documentos institucionais e históricos toma corpo.

Dessa perspectiva teórica, a DIPBA - e os "arquivos da repressão", de modo geral - é tomada, neste trabalho, como uma comunidade discursiva, o que permite certa regularidade discursiva, na medida em que é, de acordo com Vitale, que retoma trabalhos de Maingueneau, considerada "produtor de discursos, de modo que sua organização, suas tarefas de inteligência e sua própria existência enquanto grupo, foram concebidas como indissociáveis de suas práticas discursivas". Seguindo esta linha de pensamento teórico, portanto, é que se apresentam todos os sete capítulos/trabalhos que compõem os resultados da pesquisa e dão forma ao livro.

Interessante notar que o trabalho daquele órgão de vigilância, em diferentes momentos, do pré ao pós-ditadura, institui diferenças, construídas discursivamente, no sujeito espionado: do "delinquente político", "delinquente social" ou "comunista genérico" ao "delinquente subversivo" e "delinquente terrorista", chegando, no período democrático, e acompanhando as políticas neoliberais, aos ativistas sociais da periferia, imigrantes pobres, manifestantes e desocupados. Vale ressaltar, todavia, ainda como aponta Vitale, que "a memória discursiva que conformou a comunidade da DIPBA não estava apenas integrada por um 'outro', ou antiethos, como também pela imagem de si, ou ethos, que os agentes de inteligência construíram em seus discursos”. A memória é, então, articulada às práticas discursivas da inteligência repressiva e essas caracterizações perpassam, em alguma medida, o conjunto de trabalhos.

É importante então pensar, para compreender esse processo, a memória que opera em diferentes quadros sociais, como a família, a escola, a comunidade religiosa, a classe social, a região, a nação e, neste caso, as instituições de vigilância e repressão. Pensá-la nessa perspectiva de quadro permite tomá-la, como aponta Pierre Nora (1997), como um conjunto de estratégias, de disputas que se justificam muito mais pelo que se faz da memória que por ela mesma. A memória, nesse sentido, no contraponto da história, mesmo que social, apresenta e representa uma coletividade e, por isso, nos permite articular às comunidades discursivas e às práticas que se estabelecem no seu interior.

Há, portanto, um ponto nodal entre o trabalho da memória coletiva e as práticas discursivas que subjazem os sujeitos. Jean-Jacques Courtine, em seus trabalhos, articula a problemática da memória aos aspectos discursivos ao mostrar que é na linguagem que se produz a memória e seus efeitos. Para ele, a memória discursiva concerne à existência histórica do enunciado no interior das práticas discursivas: "os objetos que chamamos de 
'enunciados', na formação dos quais se constitui o saber próprio a uma FD, existem no tempo longo de uma memória, enquanto que as formulações são tomadas no tempo curto da atualidade de uma enunciação" (COURTINE, 1986, p. 107).

Articular a problemática da memória aos aspectos linguageiros e discursivos é também o que torna este trabalho singular. Como sabemos, são diversos os campos de saber que se debruçam sobre as ditaduras e os arquivos por elas produzidos, mas são os estudos discursivos que os tomam enquanto produção de (efeitos de) sentidos, analisando aspectos linguísticos, de gênero discursivo e texto, articulando-os aos sujeitos que se inscrevem nessas práticas. É justamente esse o ponto teórico-metodológico que constitui a obra, na sua organização, e cada texto que a constitui.

Interessante, então, observar, como nos mostra o artigo de Vitale, intitulado "Vigiladores y espías. Imagen de sí, memoria y esperticia en el archivo DIPBA”, que serve como marco teórico-analítico e perpassa todas as demais discussões, que os documentos que preenchiam o Arquivo da DIPBA faziam entrever um discurso de inteligência, mesmo em distintos momentos (períodos de ditadura ou democracia). A emergência de uma comunidade discursiva - as comunidades de inteligência - é vista por meio da análise de enunciados que se constituíam como um discurso especializado a partir de quatro fatores, como mostra a autora: a) sociodiscursivos: os produtores do discurso de inteligência são especialistas que desenvolvem sua profissão num âmbito institucional determinado; b) textuais: aqui são centrais os gêneros discursivos próprios à Inteligência e às convenções retóricas que regulam a construção do discurso especializado, particularmente o informe de inteligência; c) cognitivos: o marco conceitual próprio à Inteligência que é concebida como uma "disciplina científica"; d) terminológicos: a inteligência carrega uma terminologia própria que a DIPBA buscou unificar.

Seu propósito foi caracterizar o ethos dos agentes da DIPBA atrelado aos gêneros próprios da inteligência policial e, ao mesmo tempo, observar a regulação em torno das práticas de escritura. Nesse sentido, faz entrever uma memória discursiva em torno de uma imagem que, pelos próprios agentes, pode ser classificada como de "especialistas qualificados" e, discursivamente, constitui-se como comunidade. Na produção de um discurso especializado, então, os gêneros próprios da inteligência, os informes e documentos oficiais, emergem como constituintes, na atribuição dada por Dominique Maingueneau - “A pretensão desses discursos, assim por nós chamados de 'constituintes', é de não reconhecer outra autoridade além da sua própria, de não admitir quaisquer outros discursos acima deles" (2008, p. 37). Nesse sentido, percebe-se a escritura da Inteligência como uma arte, que institui um saber teórico que articula a própria inteligência policial com o relato próprio de um gênero jornalístico (com a estrutura de pirâmide invertida e a recorrência a fontes) associado às práticas capitalistas, que estabelece normas para estruturar e redigir seus informes e suas mensagens, e faz emergir um ethos que se conforma também a um corpo terminológico e a uma "linguagem técnica da especialidade". O ethos do agente é, dessa forma, aquele do "especialista"; por outro lado, como contraponto, um antiethos atravessa essa memória discursiva marcada pela fórmula "subversão".

A partir desse panorama e sustentando a problemática em torno da comunidade discursiva da DIPBA é que se articulam os demais trabalhos que compõem a obra e instauram a organicidade que sustenta toda a investigação conjunta. Mariano Dagatti, em "El informante de la DIPBA. Redacción científica y notación testimonial en los informes de inteligencia de la DIPBA sobre el 'factor estudiantil' (1959-1974)", apresenta resultados de seu estudo de informes de inteligência produzidos pela DIPBA a partir da vigilância 
a estudantes da Universidad Nacional de La Plata, realizados entre 1959 e 1974. Seu trabalho vai ao encontro das investigações de Vitale, na medida em faz notar a emergência de um gênero híbrido que conjuga genericamente a redação científica, marcada pela objetividade, e a crônica jornalística, sustentada na autenticidade, na construção de sua verossimilhança que dá ao informante um efeito de transparência informativa. Desse modo, vê-se a construção de um ethos objetivo, neutro e transparente, que possibilita o aparecimento de um dizer verdadeiro, único e monológico.

$\mathrm{Na}$ esteira dessa discussão, María Elsa Bettendorff, em "La palabra capturada: acerca de la polifonia y la heterogeneidade enunciativa en los legajos de inteligencia de la DIPBA (período CONINTES)", analisa os arquivos que tratam do Plano CONINTES - Conmoción Interna de Estado -, que, no início dos anos 1960, precedeu a Doutrina de Segurança Nacional, a repressão ilegal e o terrorismo de Estado, centrando seu foco de perseguição em militantes peronistas. Sua análise institui o paradoxo: a produção de informação pela DIPBA que a caracteriza como comunidade discursiva se materializa em textos de configuração polifônica (a inscrição da palavra alheia) e em documentação marcadamente heterogênea, mas que instaura, por sua vez, ao mesmo tempo que mascara, um ponto de vista unívoco, uma vez que subordina o conjunto de enunciados a uma matriz monológica própria dos gêneros constituintes inscritos em contextos sócio-históricos de tendência autoritária.

O quarto capítulo constitui-se no trabalho de Paulina Bettendorff, intitulado "El polícia-espectador en el archivo de la DIPBA. Efectos de generacidad en informes de vigilancia a cineclubes y teatros independientes". Analisando os informes sobre cineclubes e teatros independentes, a autora mostra que tal gênero não se fixa num modelo estável, na medida em que adota diferentes maneiras de dizer próprias de outros gêneros, o que constitui um efeito de genericidade - os deslocamentos próprios de um gênero quando colocado em relação com um ou mais gêneros tanto na produção quanto na recepção-interpretação. Na investigação do cinema e do teatro, os agentes se valem de resenhas, notícias em jornal e descrições para produzir a informação; desse modo, ao recorrer a outros gêneros e à palavra alheia, a estabilidade e a objetividade não passam de pretensão do enunciador, que torna opaco os textos produzidos.

Também no campo da arte e da intelectualidade, o trabalho de Nicolás Chiavarino, "La designación del prohibido. Informes de DIPBA sobre el Centro Editor de América Latina (1969-1978)", apresenta o estudo da memória discursiva que se estabelece a partir da designação e os efeitos de sentido outorgados pelos informes aos produtos culturais submetidos à repressão político-ideológica, ou seja, os documentos da DIPBA sobre o controle cultural. Ao tratar de dois contextos autoritários (os anos de 1969 e 1978), o autor faz ver que distintas condições de produção desses informes dão lugar a transformações e continuidades na construção de objetos discursivos e na sua tematização. As análises demonstram uma oposição entre os textos que devem ser proibidos, marcados como "de ordem marxista / propaganda comunista", e textos que devem circular, etiquetados como "didáticos / não ideológicos"; desse modo, uma formação discursiva própria da repressão cultural procurava estabelecer uma relação entre o setor do campo cultural submetido à repressão político-ideológica e as organizações armadas.

Na sequência, Adriana Minardi apresenta seu trabalho "Efectos de archivo: memorias retórico-argumentales y formas de persecusión política. Las transferencias ideológicas en torno al disidente en el archivo de la DIPBA", no qual discute a memória discursiva republicana (associada às memórias do nacionalismo espanhol) no arquivo da DIPBA. Retomando a discussão em torno dos "arquivos da repressão", e associando-os a lugares 
de memória, na esteira dos trabalhos de Pierre Nora, na sua tríplice dimensão - material, simbólica e funcional -, observa a emergência de um porta-voz da repressão que tem ancoragem no nacionalismo tradicionalista e produz posicionamentos entre a memória discursiva nacional católica do regime franquista e o neoliberalismo da última ditadura militar argentina, o que permite a caracterização do arquivo em torno de uma mesma comunidade discursiva e, por consequência, de uma mesma memória. Sendo assim, a autora faz ver que as fórmulas utilizadas para caracterizar o inimigo interno republicano (também considerado estrangeiro) são as mesmas utilizadas pelo Franquismo em seu registro policial - o inimigo interno, aqui e lá, é o comunista, o estrangeiro, o marginal e o anticatólico -, caracterizando um ethos associado a valores morais e um antiethos a republicanos.

O sétimo e último capítulo - "La noche de los Lápices. Del espionaje político em torno a su memorialización", de Alex Colman -, por fim, trata do episódio bastante conhecido como "Noche de los lápices". Observando documentos que realçam o caráter de transição da ditadura para a democracia, o autor verifica um processo de transformação na elaboração da memória coletiva a partir de distintas interpretações e usos políticos do acontecimento: i) a apropriação predominante de categorias discursivas próprias dos Direitos Humanos acerca das vítimas da ditadura, que estão vinculadas ao chamado "mito da vítima inocente"; ii) intervenções "de tipo afetivas" que descrevem a agressividade dos estudantes em relação às forças policiais; iii) e o acento na "militância revolucionária" que emerge a partir dos informes de caráter "Político".

Como se vê, pela breve descrição das partes (capítulos), ainda que cada um se valha de acontecimentos particulares e distintos recortes cronológicos, é possível perceber uma organicidade no trabalho em torno da memória que emerge dos e ao mesmo tempo constitui os arquivos da repressão, aqui representados pela DIPBA. As análises dos diferentes documentos confirmam a hipótese inicial de que a DIPBA constitui uma comunidade discursiva e, por consequência, faz entrever uma memória discursiva comum aos "arquivos da repressão" argentina. Nesse ponto, os gêneros analisados, informes da repressão, articulam propriedades próprias da inteligência policial ao relato jornalístico (estrutura, fontes, voz alheia) e por entre a investigação policial e vozes alheias (os antiethos) faz intervir um discurso monológico.

É, portanto, fundamental ressaltar a importância deste trabalho para a compreensão da memória da repressão argentina, com a reflexão sobre período de exceção, a partir de um trabalho com arquivos, que tem particularidade naquele país ao mesmo tempo em que estabelece relações com contextos próximos na América do Sul. Sua relevância, ademais, produz efeitos no Brasil, na medida em que o aparato teórico-metodológico é exemplar para as reflexões em torno de nossa particularidade; além disso, como já apontamos, incita nossos pesquisadores a reivindicar ainda mais o acesso às informações do período ditatorial brasileiro, de modo que possamos também aqui instituir políticas de memória. É justamente por esses aspectos que recomendamos a leitura atenta deste trabalho, tanto por pesquisadores dos estudos discursivos quanto por aqueles que se interessam pela problemática da repressão no contexto sul-americano.

\section{Referências}

COURTINE, J-J. Mémoire et discours. Sédiments. Montréal, 1986, p. 97-117. MAINGUENEAU, D. Cenas da enunciação. São Paulo: Parábola Editorial, 2008. Trad. 


\section{Conexão Letras}

Maria Cecília Pérez de Souza-e-Silva, Nelson P. da Costa e Sírio Possenti.

NORA, P. Entre Mémoire et Histoire: la problématique des lieux. In: NORA, Pierre (Dir.). Les lieux de mémoire: La République; La Nation; Les France. t. 1. Malesherbes:

Quarto Gallimard, 1997, p. 23-43.

VITALE, M. A. (Org.) Vigilar la sociedad. Estudios discursivos sobre inteligencia policial bonaerence. Buenos Aires: Biblos, 2016.

Recebido em: 05/09/2017 Aceito em: 27/09/2017 